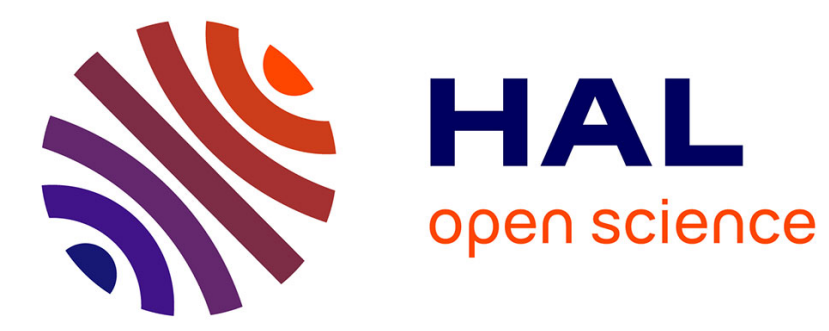

\title{
Metric Scale Study of the Bonded Concrete-Rock Interface Shear Behaviour
}

\author{
Marion Bost, Hussein Mouzannar, Fabrice Rojat, Grégory Coubard, \\ Jean-Pierre Rajot
}

\section{- To cite this version:}

Marion Bost, Hussein Mouzannar, Fabrice Rojat, Grégory Coubard, Jean-Pierre Rajot. Metric Scale Study of the Bonded Concrete-Rock Interface Shear Behaviour. KSCE Journal of Civil Engineering, 2019, 34p. 10.1007/s12205-020-0824-5 . hal-02441859

\section{HAL Id: hal-02441859 \\ https://hal.science/hal-02441859}

Submitted on 16 Jan 2020

HAL is a multi-disciplinary open access archive for the deposit and dissemination of scientific research documents, whether they are published or not. The documents may come from teaching and research institutions in France or abroad, or from public or private research centers.
L'archive ouverte pluridisciplinaire HAL, est destinée au dépôt et à la diffusion de documents scientifiques de niveau recherche, publiés ou non, émanant des établissements d'enseignement et de recherche français ou étrangers, des laboratoires publics ou privés. 
Metric Scale Study of the Bonded Concrete-Rock Interface Shear Behaviour

Marion Bost ${ }^{1 *}$, Hussein Mouzannar ${ }^{2}$, Fabrice Rojat $^{3}$, Grégory Coubard $^{4}$, Jean-Pierre Rajot ${ }^{5}$

${ }^{1}$ Dr, Ing, University of Lyon, IFSTTAR, GERS, RRO, F-69675, Lyon, France - E-mail : marion.bost@ifsttar.fr

${ }^{2}$ Dr, Ing, University of Lyon, IFSTTAR, GERS, RRO, F-69675, Lyon, France - E-mail : hussein.mouzannar@hotmail.com

${ }^{3}$ Dr, Ing, CEREMA, F-69500, Lyon, France-E-mail: fabrice.rojat@cerema.fr

${ }^{4}$ Ing, EDF, Hydraulic Engineering Center, F - 73373, Le Bourget-du-Lac, France - E-mail : gregory.coubard@edf.fr

${ }^{5}$ Pr, University of Lyon, IFSTTAR, GERS, RRO, F-69675, Lyon, France - E-mail : jean-pierre.rajot@ifsttar.fr

* Corresponding author

\section{Abstract}

The shear strength of concrete-rock interface is a key factor to evaluate the stability of gravity dams. The shear strength assessment by achieving tests on small samples gives values different from those estimated by back-analysis on the existing dams. This work aims to study the shear behaviour of concrete-rock interface in the metric scale. Five direct shear tests were performed on bonded meterscale concrete-granite interfaces in the range of normal stresses to which gravity dam foundation is subjected. Specific instrumentation were installed to monitor the failure mechanisms during the tests. The five concrete-rock interfaces have not broken by shearing of materials (concrete, rock) in the shear plane imposed by the test device, but by debonding of the contact between concrete and rock. Considering roughness of the contact surface in the decimeter scale and the results of shear tests carried out in the same scale, the decimeter scale is demonstrated to correspond to the elementary surface for the shear behaviour of the metric concrete-rock interface. According to the level of normal stress, the stiffness of both materials and the main asperities in the decimeter scale, different failure mechanisms occur locally to justify the overall failure in the metric scale.

Key words:

Concrete-rock interface, Bond, Shear strength, Metric direct shear test, Scale effect 


\section{Introduction}

Concrete gravity dams are usually founded on rock. This type of concrete dams relies on the concrete weight to withstand the forces imposed on the dam. The stability of a gravity dam is justified against the downstream sliding on pre-existing planes of weakness in the rock foundations, in the concrete abutments and at the concrete-rock interface (Schleiss and Pougatsch, 2011; CFBR, 2012). For the latter failure location, concrete-rock shear strength is one of the specific geotechnical factors that may require consideration (Brown, 2017; France: CFBR, 2012; Canada: CDA, 2007; 2013; Norway and Sweden: Gutierrez, 2013; USA: FERC, 2002). In France, the French Committee of Dams and Reservoirs (CFBR, 2012) recommends to take conventional conservative values. However, with modern safety regulations in France and in many other areas of the world such as in Sweden (Krounis et al., 2015), the stability of old gravity dams, which until now, is based on a safe estimation of the shear strength of the interface between rock and concrete, is not verified anymore.

As the in situ tests to evaluate rock-concrete shear strength are complex, time consuming, and expensive (Barla et al., 2011; Andjelkovic et al., 2015), this strength is usually evaluated by direct shear testing in the laboratory on size-limited concrete-rock samples. This method is consistent with a common model for assessing the sliding stability of concrete dams in which the shear strength is considered homogeneous at the entire dam foundation interface and simultaneously mobilized at the time of failure (Ruggeri et al., 2004; Krounis, 2016). The reliability of such laboratory measurements to be representative of the concrete-rock shear strength in the metric scale is however questioned due to a potential scale effect (EPRI, 1992; Ruggeri et al., 2004; CFBR, 2012). The shear behaviour at the concrete-rock interface is moreover concerned by three phenomena acting locally differently on the concrete-rock contact (Saiang et al., 2005): debonding, asperity degradation, sliding with friction.

Scale effect has already been widely investigated with rock discontinuities in the field of rock mechanics (Pratt, 1974; Barton and Choubey, 1977; Bandis et al., 1981; Fardin et al., 2003; Tatone and Grasselli, 2013; Johansson, 2016) to understand the phenomenon on the rock surface roughness and on the shear behaviour of the rock discontinuities. The scale effect on the characterization of the 
rock surface roughness remains difficult to understand due to dependency on results with measurement conditions (reference measurement plan: Swan and Zongqi, 1985; measurement resolution: Cravero et al., 1995). The scale effect on the shear behavior within rock discontinuities depends not only on the surface roughness (Bandis et al., 1981) but also on the conditions of the shear test (applied normal stress: Castelli et al., 2001; material: Hencher et al., 1993). In addition, these experimental investigations were limited to rock discontinuities unbonded and smaller dimensions than those of a dam foundation.

For 30 years, several authors (Lo et al., 1990; EPRI, 1992; Kodikara et al., 1994; Gu et al., 2003; Saiang et al., 2005; Moradian et al., 2012; Gutiérrez, 2013; Tian et al., 2015; Krounis et al., 2016) attempted experimentally in laboratory to study the shear behaviour of concrete-rock interface under constant normal load conditions. Direct shear tests conducted on concrete-rock samples in the decimeter scale showed different responses at the interface according to the quantity and quality of concrete-rock bond (Lo et al., 1990; Moradian et al., 2012; Krounis et al., 2016), the roughness of the rock surface (Gutierrez, 2013), the normal stress imposed (Kodikara et al., 1994; Gu et al., 2003; Saiang et al., 2005; Tian et al., 2015), and the materials (Lo et al., 1990; EPRI, 1992). Models developed to reproduce this shear behaviour observed consider an approach based on either one failure mechanism (degradation of asperities: Barbosa, 2009; bond failure: Lo et al., 1990; Westberg Wilde and Johansson, 2013; Tian et al., 2015) or the roughness of the rock surface (Patton, 1966; Barton and Choubey, 1977; Maksimovic, 1996; Grasselli, 2001; Tian et al., 2018; Gutierrez-Ch et al., 2018; Casagrande et al., 2017). The main limits of the models are that some of them were developed for rock discontinuities without initial bond and, for others, the approach in strength is based on the assumption of simultaneous mobilization without consideration of all possible progressive failure mechanisms at the concrete-rock interface. The previous works of the authors (Mouzannar et al., 2017) demonstrate the importance of different local effects at the concrete-rock interface.

Therefore the aim of this study is to investigate the bonded concrete-rock interface shear behaviour in the scale of a gravity dam by identifying the different local failure mechanisms and the progressive strength mobilization. To achieve this goal, direct shear tests were performed in the metric scale in the 
laboratory. By this way, the test conditions are known and an appropriate instrumentation can be used to monitor strains and stresses within the specimens. In addition, a French gravity dam being usually constituted of 10 to $20 \mathrm{~m}$ wide concrete blocks, the consideration of a metric scale size appropriately represents the interface shear phenomenon occurring in the base of such a concrete gravity dam. Materials being similar to those of direct shear tests performed on a reduced scale (Mouzannar et al., 2017), the results were compared. The sizes of the samples used in these small-scale studies were 0.08 $\mathrm{m}$ for cored samples and $0.18 \mathrm{~m}$ for square samples. The shear behaviour observed in these small-scale studies was used to explain the shear behaviour in the metric scale and identify the main parameters influencing the shear behaviour of gravity dam foundations. Finally an analytical model was established to evaluate the concrete-rock shear strength in the metric scale from measurements on a reduced scale. So, in next Section, the metric scale direct shear tests performed on concrete-rock interfaces are described and in Section 3, the results are presented. In Section 4, the results between the tests in different scales are compared and an analytical model proposed to evaluate the shear strength in the metric scale with tests in laboratory on a reduced scale is proposed and discussed. The shear behaviour of the metric-scale concrete-rock interface is discussed in Section 5 and some conclusions are given.

\section{Metric scale direct shear tests of concrete-rock interfaces bonded}

Laboratory direct shear test on a large scale concrete-rock sample is an unconventional test. No standard controls the preparation procedure of this intended large sample. The test device used is described in Section 2.1. In the following sections, the materials used for the samples (Section 2.2), the stepwise process for an accurate preparation of such a large sample (Section 2.3), the instrumentation installed (Section 2.4) and the load conditions (Section 2.5) are presented.

\subsection{Test device}

The direct shear tests in the metric scale were conducted with the large shearing box at the CEREMA laboratory (France, Fig. 1). This outstanding experimental bench allows a $1 \mathrm{~m} \times 1.5 \mathrm{~m}$ surface to be 
sheared in. The operating principle is similar to that of devices working in the decimeter scale in rock mechanics laboratories (Muralha et al., 2014; ASTM, 2008). This device is thus composed of two half-boxes. The lower half-box is fixed. The upper half-box is free to move tangentially and normally to the tested surface through a hinged joint, so as to allow the movements imposed by shear distortion. The tangential displacement is applied via two hydraulic jacks with a constant displacement speed. Each of these two hydraulic jacks develops a maximum force of $2500 \mathrm{kN}$. A distribution plate placed on the upper surface of the specimen supports two hydraulic jacks, each having a maximum capacity of $1000 \mathrm{kN}$. These two jacks allow a normal force to be applied during the test. They lift a spreader beam. This spreader beam is fixed on a cradle in contact with the lower surface of the lower half-box. By this manner, it provides the reaction load. Rollers bearings between the cradle and the lower halfbox make it possible to minimize any friction generated during the translation of the spreader beam / cradle assembly owing to the displacement of the upper half-box. The normal force is thus always applied according to the vertical direction. This large shearing box was adapted to perform shear tests under constant normal stress.

The tangential displacement of the moving upper half-block is measured with two displacement transducers. The relative normal displacement between the two half-boxes is measured with four LVDT sensors located close to each vertical edge of the upper half-box. Therefore, the movement of the upper half-box due to shear distortion can be also determined. The shearing and normal efforts are measured by load cells located on each hydraulic jack. 


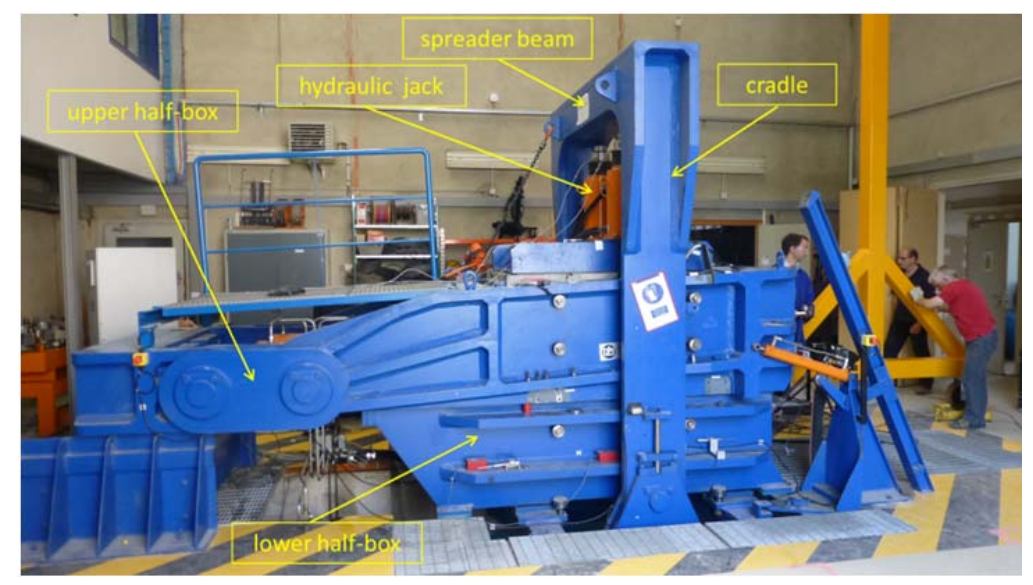

Figure 1. The large shearing box at the CEREMA laboratory (France).

2.2. Constituent materials for samples to be tested

To compare the test results with measurements of concrete-rock interface shear strength in smaller scales, the same constituent materials as in Mouzannar et al. (2017) were used for the samples to be tested.

The rock type was thus granite. Large granite rock blocks were selected and sampled in the same quarry in France (Corrèze), each one having an unweathered natural rough surface with dimensions equal to $1.5 \mathrm{x} 1 \mathrm{~m}^{2}$. The quality of the rock surfaces was similar to this of the chosen surfaces for gravity dam rock foundation in France (EDF, 2012). With the exception of a block (sample I8) where the granite presents a slight alteration in the mass, all other blocks have a healthy unaltered granite on the surface of the rock to be tested. The physical and mechanical characteristics of this rock are summarized in Table 1.

The mixture of concrete used, chosen according to an analysis of that used for existing French concrete gravity dams, is shown in Table 2. The physical and mechanical characteristics of this concrete are summarized in Table 1. 
Table 1. Physical and mechanical characteristics of granite and concrete.

\begin{tabular}{|c|c|c|c|}
\hline & Compressive strength & Tensile strength & Density \\
\hline Granite & $133 \mathrm{MPa}$ & 10.21 MPa & $2608 \mathrm{~kg} / \mathrm{m}^{3}$ \\
\hline Coefficient of variation & $\begin{array}{c}5.90 \%-10 \text { samples } \\
\text { tested }\end{array}$ & $\begin{array}{c}13.90 \%-5 \text { samples } \\
\text { tested }\end{array}$ & $\begin{array}{c}0.47 \%-15 \text { samples } \\
\text { tested }\end{array}$ \\
\hline Concrete & $43.4 \mathrm{MPa}$ & $3.75 \mathrm{MPa}$ & $2370 \mathrm{~kg} / \mathrm{m}^{3}$ \\
\hline Coefficient of variation & $\begin{array}{c}1.60 \%-9 \text { samples } \\
\text { tested with } 3 \text { different } \\
\text { pouring phases }\end{array}$ & $\begin{array}{l}7.10 \%-9 \text { samples } \\
\text { tested with } 3 \text { different } \\
\text { pouring phases }\end{array}$ & $\begin{array}{l}0.22 \%-9 \text { samples } \\
\text { tested with } 3 \text { different } \\
\text { pouring phases }\end{array}$ \\
\hline
\end{tabular}

Table 2. Concrete formulation.

\begin{tabular}{|l|c|}
\hline \multicolumn{1}{|c|}{ Component } & Quantity $\left(\mathrm{kg} / \mathrm{m}^{3}\right)$ \\
\hline Cement CEMI 52.5R & 280 \\
\hline Sand 0/4 mm & 650 \\
\hline Washed-out sand 0/2 mm & 150 \\
\hline Aggregate $11.2 / 22.4 \mathrm{~mm}$ & 780 \\
\hline Aggregate $4 / 11 \mathrm{~mm}$ & 330 \\
\hline Additive - OPT 203 & 2.80 \\
\hline Water & 157 \\
\hline
\end{tabular}

\subsection{Preparation of the samples}

Similarly with the test conditions in Mouzannar et al. (2017), the best-fit plane of the rock surface of the concrete-rock interface was chosen as the shearing surface. In order to determine the position of this plane for each rock surface of $1 \mathrm{~m}$ x $1.5 \mathrm{~m}$, squares were fixed to the blocks corners (Fig. 2(a)). Then the apparatus ATOS Compact Scan, based on the technique of digital image correlation with projection of textured light, was used to sweep the rock surfaces including the squares (Fig. 2(b)). The sensors used and the measurement distance were chosen to obtain a resolution of $0.25 \mathrm{~mm}$ recommended in previous researches (Tatone et al., 2010). After processing the data, the topography of the surface can be reproduced and the roughness parameters calculated. The best-fit plane of the rock surfaces was determined with the least squares method applied to the heights of the surfaces 
topography. This plane corresponds to the midplane of the rock surfaces and of the rock-concrete interfaces. It was located relative to the plane of the four squares formerly installed by determining numerically the distance between both planes on each corner of the blocks (Fig. 2(c)). Afterward, the midplane was drawn on the four lateral faces in order to materialize it on each rock block during the next steps of the specimen preparation.

After the preparation of the rock part of the specimen, the concrete part was poured on each natural rock surface (Fig. 2(f)). For this purpose, the position of each rock block was adjusted in order to have the midplane of its natural surface previously determined in a horizontal plane. Film faced plywoods were set vertically around the rock part of each specimen as formworks (Fig. 2(d)). Their upper level was adjusted to have the distance between the upper level of the plywoods and this best-fit plane equal to the height of the upper half-box of the test device. By this way, the midplane of each concrete-rock interface also manufactured corresponding to the sample plane to be sheared. In order to avoid concrete shrinkage during hardening and install anchorage for post-test transport, the top of the concrete part was reinforced by a steel cage leaving a $0.20 \mathrm{~m}$ thick unreinforced concrete layer adjacent to the rock-concrete interface (Fig. 2(e)). 

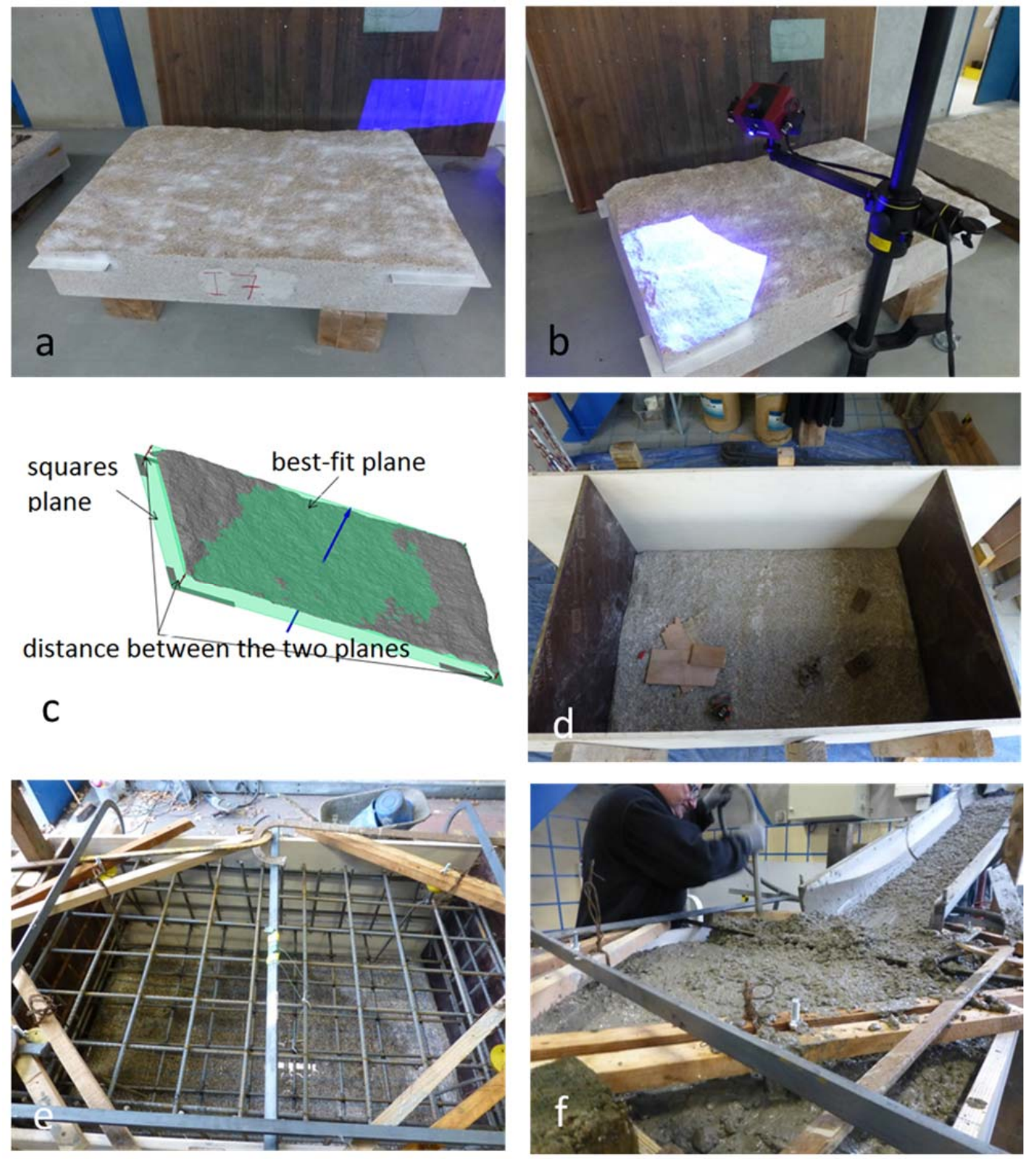

Figure 2. Step-by-step pictures schematic of sample preparation process : (a) fixation of four squares, (b) scan of the rock surface, (c) location of the best-fit plane, (d) installation of formworks, (e) installation of steel reinforcement, (f) concrete pouring.

\subsection{Instrumentation}

To study thoroughly the shear behaviour of concrete-rock interface and to observe possible cracking mechanisms and debonding propagation along this interface, different instrumentation devices were utilized during the large scale direct shear tests, set up both within the samples and on their lateral sides (Mouzannar et al., 2016). 


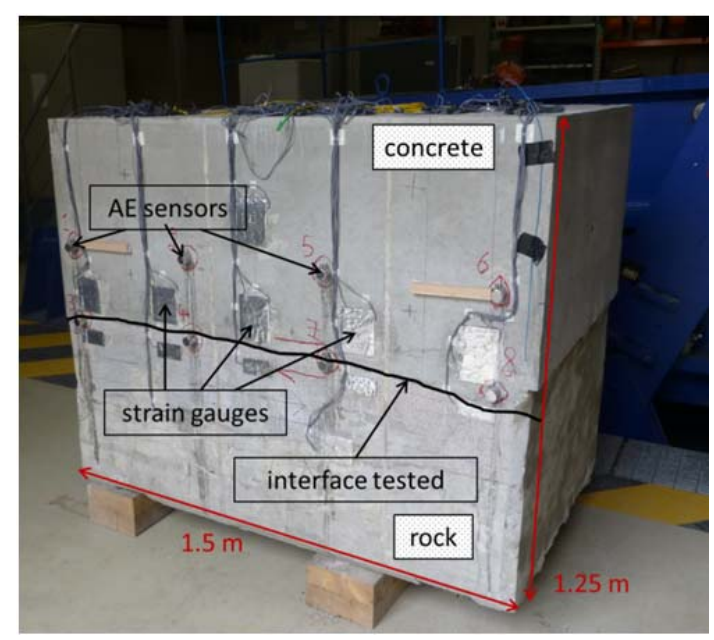

Figure 3. Lateral view of the instrumentation devices set up on a concrete-rock sample.

Strain gauges and acoustic emission (AE) sensors were installed on the lateral sides of concrete parts, close to the interfaces (Fig. 3). A strain gauge can measure strain in only one direction. To determine the three independent components of plane strain, three independent strain gauges positioned in a rosette were used for each measurement point. Thereby local deformation was observed due to the relaxation of stresses in the blocks at the time of locally breaks occurred somewhere along the interfaces. AE data analysis (amplitude, rise time, energy) allows identifying damage mechanisms and locating them in the tested concrete volume (Chataigner et al., 2017). This non-destructive technique allowed us to locate crack opening at both the interfaces between rock and concrete and within the materials.

An optical fiber was embedded in the concrete parts during the samples preparations with a serpentine form in a horizontal plane, $50 \mathrm{~mm}$ above the best-fit plane of the rock surfaces (Fig. 4). The principle of Rayleigh back-scattering used for these experiments allows the quasi-continuous measurement of strain profiles along the fiber (Khadour et al., 2017). In this way, deformation evolution was measured in the concrete close to the concrete-rock interfaces. 


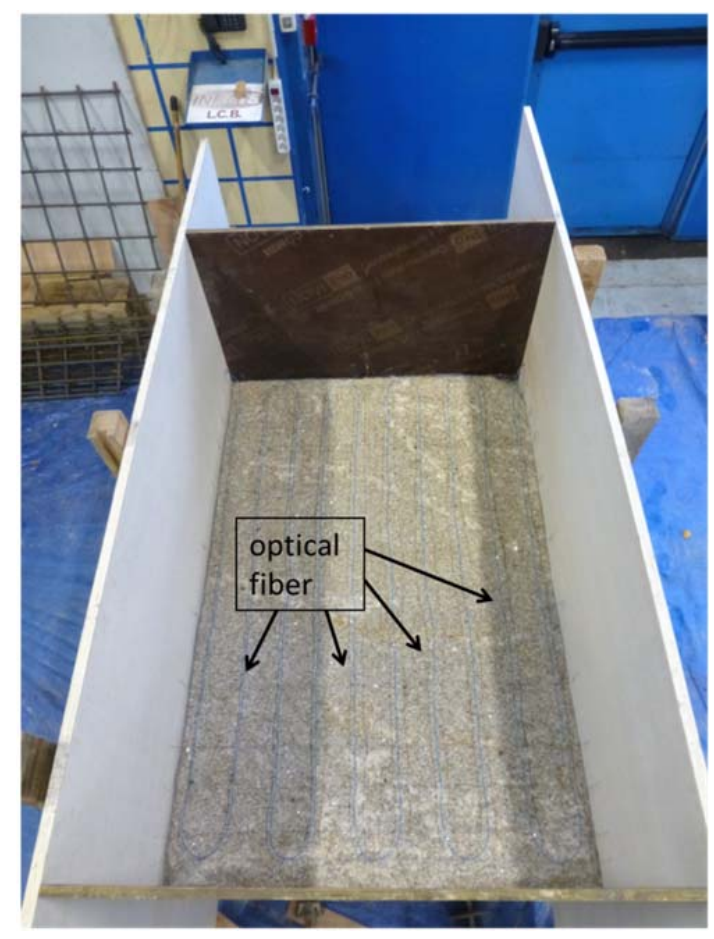

Figure 4. Installation of the optical fiber close to a rock surface before concrete pouring.

The measurements with the strain gauges, the emission acoustic sensors, the transducer sensors, the LVDT sensors and the load cells were synchronized. The acquisition frequency was chosen equal to $10 \mathrm{~Hz}$. For optical fiber system, a measurement was performed after each load step of $100 \mathrm{kN}$.

\subsection{Load conditions}

To compare the results with those obtained with direct shear tests in smaller scales, the load conditions are similar to those of Mouzannar et al. (2017). The direct shear tests were performed with a constant normal stress applied on the concrete/rock interface. During the tests, the constant shear displacement rate applied was equal to $0.1 \mathrm{~mm} / \mathrm{min}$. This value is consistent with the value recommended in Muralha et al. (2014) for rock discontinuities. The prepared specimens were tested 28 days after concrete pouring.

Five samples within a concrete-rock rectangular shear surface of $1.5 \times 1 \mathrm{~m}^{2}$ were also tested. Four different values of normal load were used $(0.2,0.4,0.6$ and $1 \mathrm{MPa})$, which correspond to the values generated by usual heights of concrete gravity dams. Two large scale direct shear tests were performed under normal stress of 0.6 MPa (samples I7 and I2), one under normal stress 0.2 MPa (sample I9) and 
one 0.4 MPa (sample I8). The fifth sample (I1) was first tested under normal stress $1 \mathrm{MPa}$ but the capacity of the shearing device was insufficient to break the interface. The sample was unloaded and a new shear test was conducted under a lower normal stress value of $0.6 \mathrm{MPa}$.

3. Metric scale direct shear tests: results

Concrete-rock interface failed for each direct shear test performed in a large scale. 


\subsection{Damage observations}
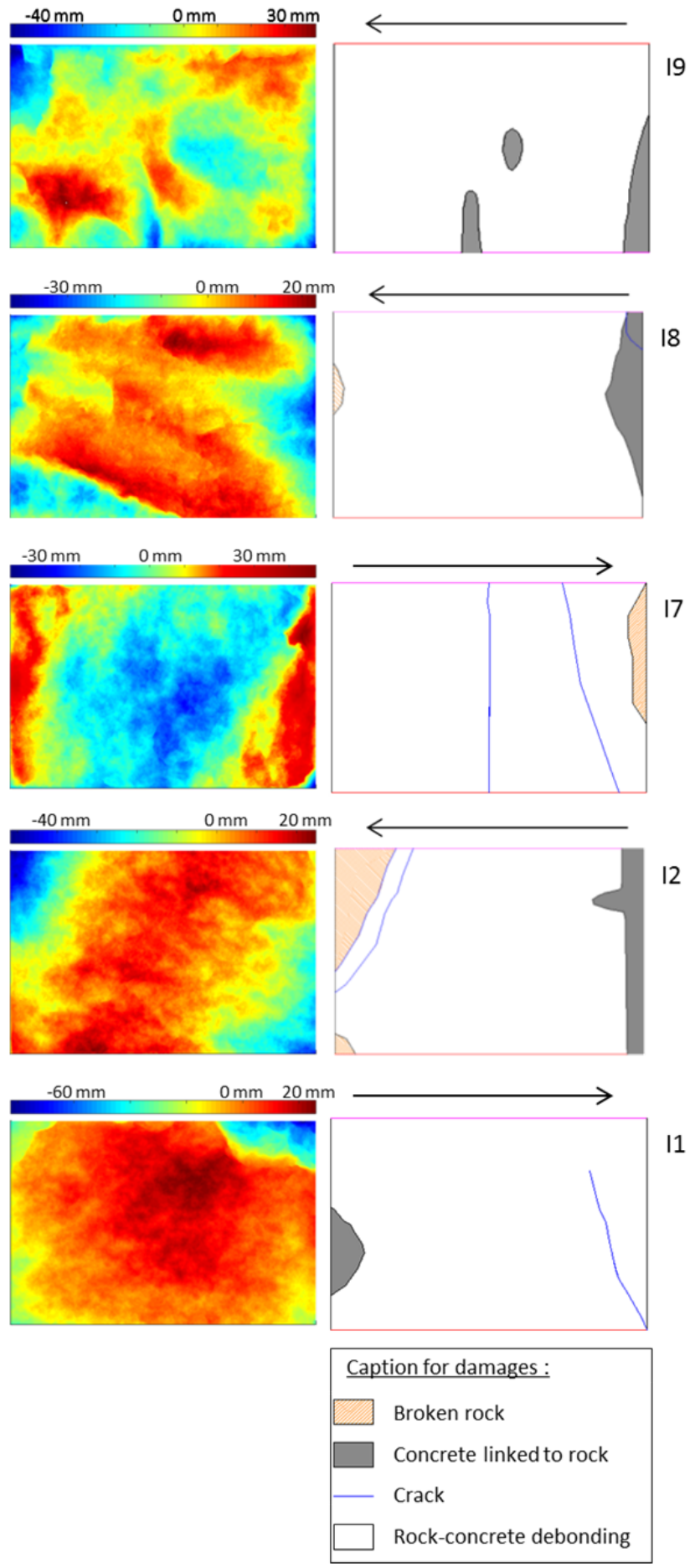

Figure 5. Initial topography of the five rock surfaces to be tested (on the left) and damages on the five rock surfaces after direct shear test (on the right) (black arrow $=$ shear direction). 
Table 3. Damage description after the five direct shear tests.

\begin{tabular}{|c|c|l|}
\hline Test & $\begin{array}{c}\text { Normal stress } \\
\mathrm{MPa}\end{array}$ & \multicolumn{1}{c|}{ Damage description } \\
\hline I9 & 0.2 & $\begin{array}{l}\text { Complete failure of the concrete-rock contact, except for two rocky } \\
\text { depressions where concrete failed }\end{array}$ \\
\hline I8 & 0.4 & $\begin{array}{l}\text { Complete failure at the level of the concrete-rock contact, except for a } \\
\text { rocky depression where concrete failed and a rocky bump where rock } \\
\text { failed. On 70\% of the concrete surface, rock lenticles are stuck }\end{array}$ \\
\hline I7 & 0.6 & $\begin{array}{l}\text { Complete failure of the concrete-rock contact, except in a rocky crest on the } \\
\text { opposite-to-push side where rock failed. }\end{array}$ \\
\hline I2 & 0.6 & $\begin{array}{l}\text { Complete failure of the concrete-rock contact, except in a rocky crest on the } \\
\text { opposite-to-push side where rock failed and a rocky depression on the push } \\
\text { side where concrete failed }\end{array}$ \\
\hline I1 & 1, then 0.6 & $\begin{array}{l}\text { Complete failure of the concrete-rock contact except in a rocky depression } \\
\text { on the push side where concrete failed }\end{array}$ \\
\hline
\end{tabular}

By comparing the rock surfaces sheared of the samples tested, the heterogeneity of the main topography of these surfaces is highlighted (Fig. 5). While some have a single main asperity over the entire surface (concave: I1, I2; convex: I7) with an amplitude of a few centimeters, others have local asperities that dot the rocky surface (I9, I8) with an amplitude of the same order. However, whatever the sample, except within random local rocky or concrete crests, the samples failure occurred at the concrete-rock contact and not along the shear plane (Table 3). Consequently the failure mechanism of the concrete-rock interface corresponds overall to a debonding of the concrete-rock contact and not a rupture within the materials. Failure in materials develops only in localized asperities or at the extremities of the interface (Fig. 5 and Table 3). In particular, it can be observed that cracks developed in concrete on the push side for four samples (I9, I8, I2 and I1). For the sample I7, in this location, there is a rocky crest that could have prevented this failure mechanism. 
3.2. Load - displacement curves

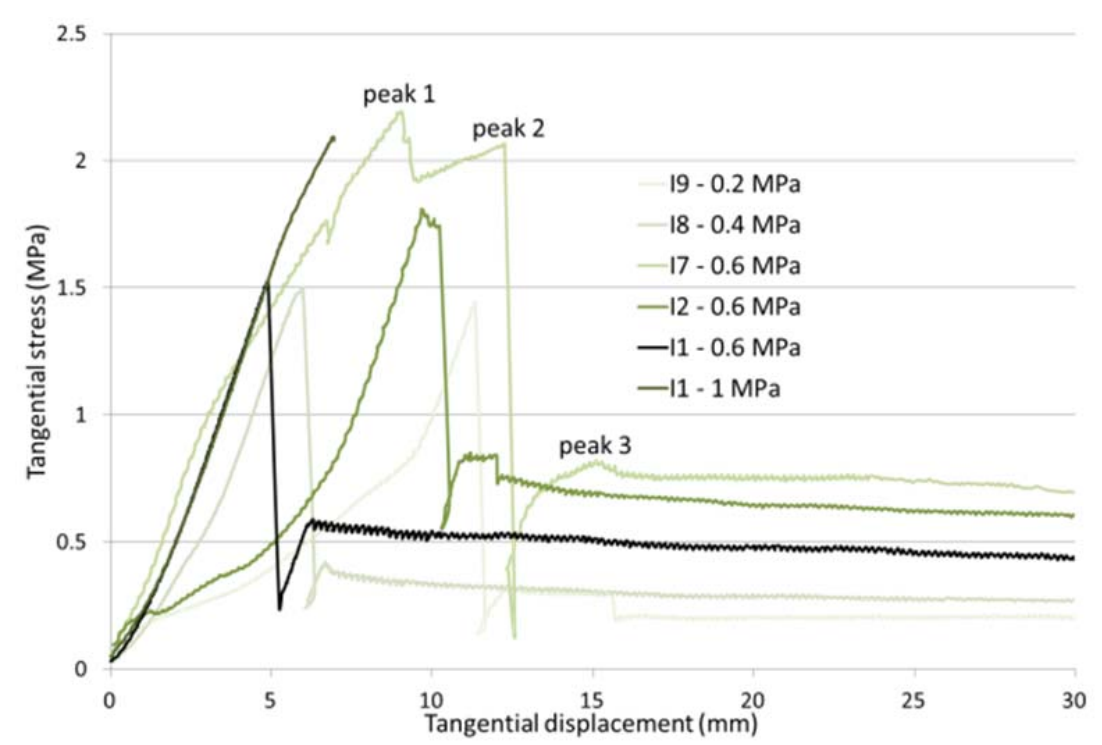

Figure 6. Shear stress versus tangential displacement for the five direct shear tests.

The typical relationship between shear stress and shear displacement of each test shows that, whatever the normal stress, the shear stress steadily increases until a peak, then drops sharply (Fig. 6). This decrease was noted during the shear tests with a strong audible sound. Thereafter, the shear stress again increases up to a much smaller peak, followed by a gradual decrease to a residual value. During this last decrease, according to normal displacement sensors, the relaxation of dilatancy is observed. The sharp decrease and the noise are typical of a brittle failure (Tian et al., 2015). According to similar results of Saiang et al. (2005) and Moradian et al. (2012), the explanation of this observation is bond failure of the concrete-rock interface. The gradual decrease after the last peak is representative of residual shear behaviour for an open discontinuity (Zhao et al., 2018). After debonding, the shear stress is generated along the interface by the friction between both rock and concrete surfaces.

To be accurate, it can be noticed that, for the samples I7 and I2, the brittle failure occurs in two steps compare to the others for which a single clear first peak is observed (Fig. 6) and, for the samples I9 and 12 , the first stress peak occurs after a moderate increase of the shear stress. Both observations could be justified by a local effect of the rocky surface roughness. It is demonstrated in the next section for the sample I7. 
On the six curves, just before the first peak, the slope of the shear stress - tangential displacement curve is similar between all samples. The amplitude of the main asperities of the rock surface being similar between the five samples (Fig.5), we can equate the slope of the stress-displacement curve just before the first peak with the shear modulus of the rock-concrete interface. The shear modulus for the concrete-rock interface depends only on materials strength (concrete, rock). Considering the heterogeneity of the main topography for the five rock surfaces tested (Section 3.1) and bearing in mind the initial state of the rocky surfaces (Section 2.2), it can be deduced that the shear modulus is mobilized mainly due to an initial local mechanical interlocking between rock and concrete generated by rock grains.

\subsection{Loading-unloading and rock surface quality effects}
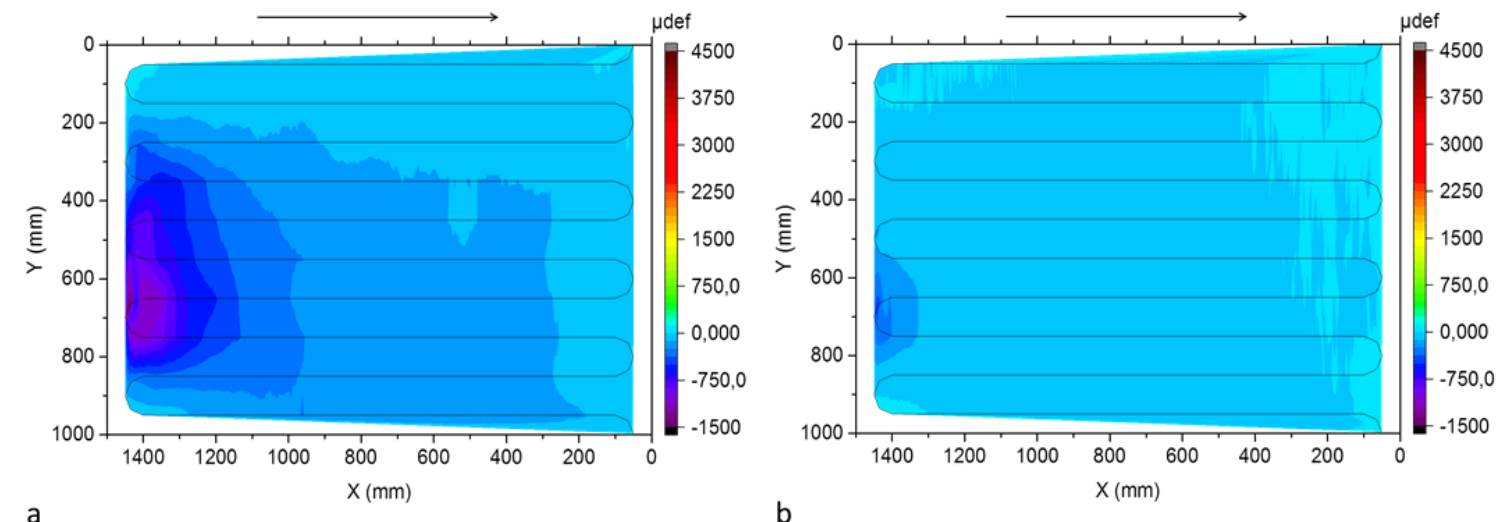

Figure 7. 2D distribution of deformation in the concrete close to the interface for the sample I1 obtained by optical fiber data analysis: (a) at the end of the first load, (b) at the end of the first unload.

The sample I1 was first sheared under a normal stress of $1 \mathrm{MPa}$ without breaking the interface (Section 2.5). After unloading, the sample was sheared a second time under a lower normal stress, 0.6 $\mathrm{MPa}$, in order to reach failure. By comparing the results between the ends of the first load and first unload, the optical fiber installed close to the interface indicated some plastic deformation localized in concrete on the push side at the end of the first load (Fig. 7). Additionally the interface broke at a peak shear stress value lower than that of the tests on the samples I7 and I2, both sheared under the same 
value of normal stress $(0.6 \mathrm{MPa})$. Thus, the interface shear strength of the sample I1 decreased due to successive shear tests. Therefore, special attention should be paid to the shear strength of the concreterock interface for the foundation of a concrete gravity dam after a significant loading-unloading cycle with reduction of the normal stress at the dam base, for example due to an exceptional earthquake or flood.

The geological description (grain color, surface weathering) of the surface of the granite blocks used to prepare samples exhibited that the granite surface of the sample I8 has a lower quality than the others. The natural rock surface used for this rock-concrete interface was weathered before sampling. This rock surface peels off more easily than the rock surface of the other samples. As a consequence, unlike other samples, the failure of sample I8 occurred only for $30 \%$ of the interface surface at the concrete-rock contact and, for the remaining $70 \%$, through the weathered granite on the surface. The peak shear strength usually increases with increasing the applied normal stress. Nevertheless, considering both samples I8 and I9 sheared under two different normal stresses, respectively 0.4 and 0.2 $\mathrm{MPa}$, the values of the interface peak strength measured for the two samples, respectively 1.48 $\mathrm{MPa}$ and $1.45 \mathrm{MPa}$, are very close. Therefore, the peak strength of the interface of sample I8 is inconsistently too low. The difference in roughness being not significant enough to justify this low value of strength for I8 (Section 3.1), the quality of the rock surface was thus confirmed to contribute to the peak shear strength of the rock-concrete interface.

To conclude, in both cases, due to successive loading-unloading steps and low quality of the rock surface, the value of the interface peak shear strength is reduced due to the lower quality of the bond at the interface. This result is consistent with similar observations in previous works (Ruggeri et al., 2012). Consequently, it confirms that the bond between concrete and rock at the interface contributes to the value of the peak shear strength for this level of normal stress. 
3.4. Shear behaviour of the concrete-rock interface for the sample I7

In this section, the manner in which each measurement was used to explain the shear behaviour of the concrete-rock interface of each sample is presented. The case of the sample I7 is chosen as example. This analysis completes the first sets of the analysis given in Mouzannar et al. (2016).

Considering the granite and concrete surfaces of the interface after the test (Figs. 8(a) and 8(b)), the failure occurred by debonding of the contact between both materials. A transversal crack propagated through rock and concrete on the opposite-to-push side.
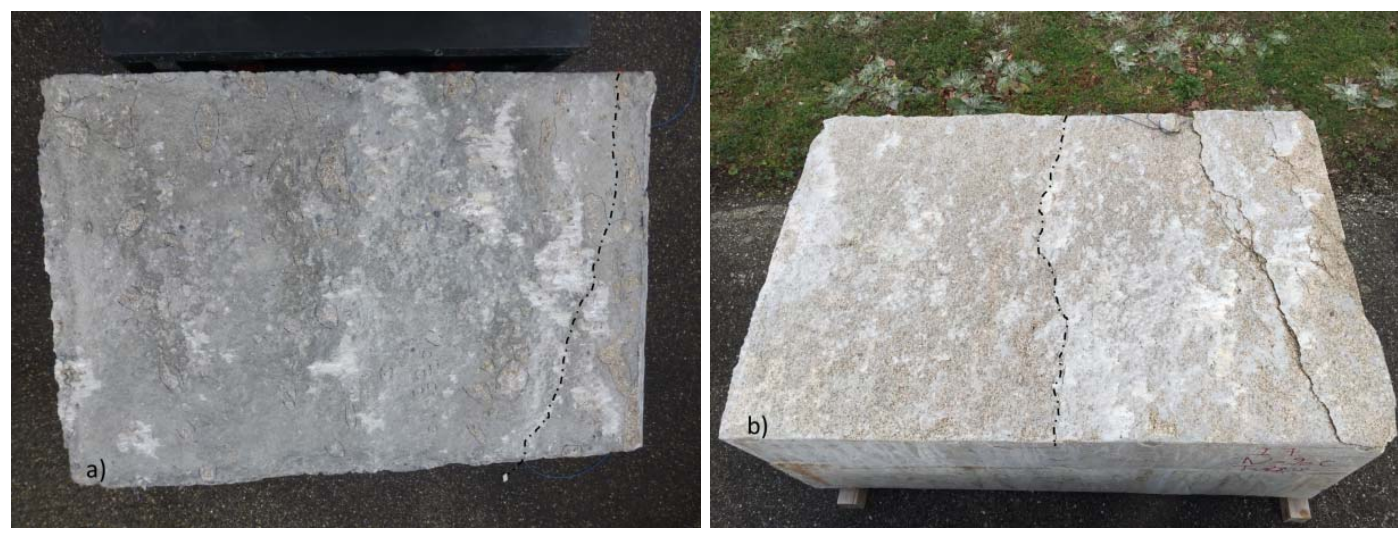

Figure 8. Concrete (a) and granite (b) surfaces of the interface debonded after the test. The dotted black lines symbolize cracks.

On Fig. 6, the relationship between the shear stress applied to the concrete-rock interface and the relative shear displacement between concrete and rock is displayed. There are three distinct stress peaks on the curve. As explained in Section 3.2, the first two peaks suggest two successive brittle failure mechanisms and the last peak, the beginning of the residual behaviour.

Fig. 9 displays the strain evolution for the vertical strain gauges (V1 - on the push side to V5 - on the opposite-to-push side) stuck on concrete along the interface (Fig. 3). The V4 and V5 vertical strain gauges, located successively on the opposite-to-push side, broke at peak 2 and peak 1, respectively. These observations agree with crack propagation through rock then concrete since the peak 1 . After peak 2, the stress relaxation observed in the strain gauges $\mathrm{V} 1$ to $\mathrm{V} 3$ is consistent with the previous explanation of a residual behaviour. 


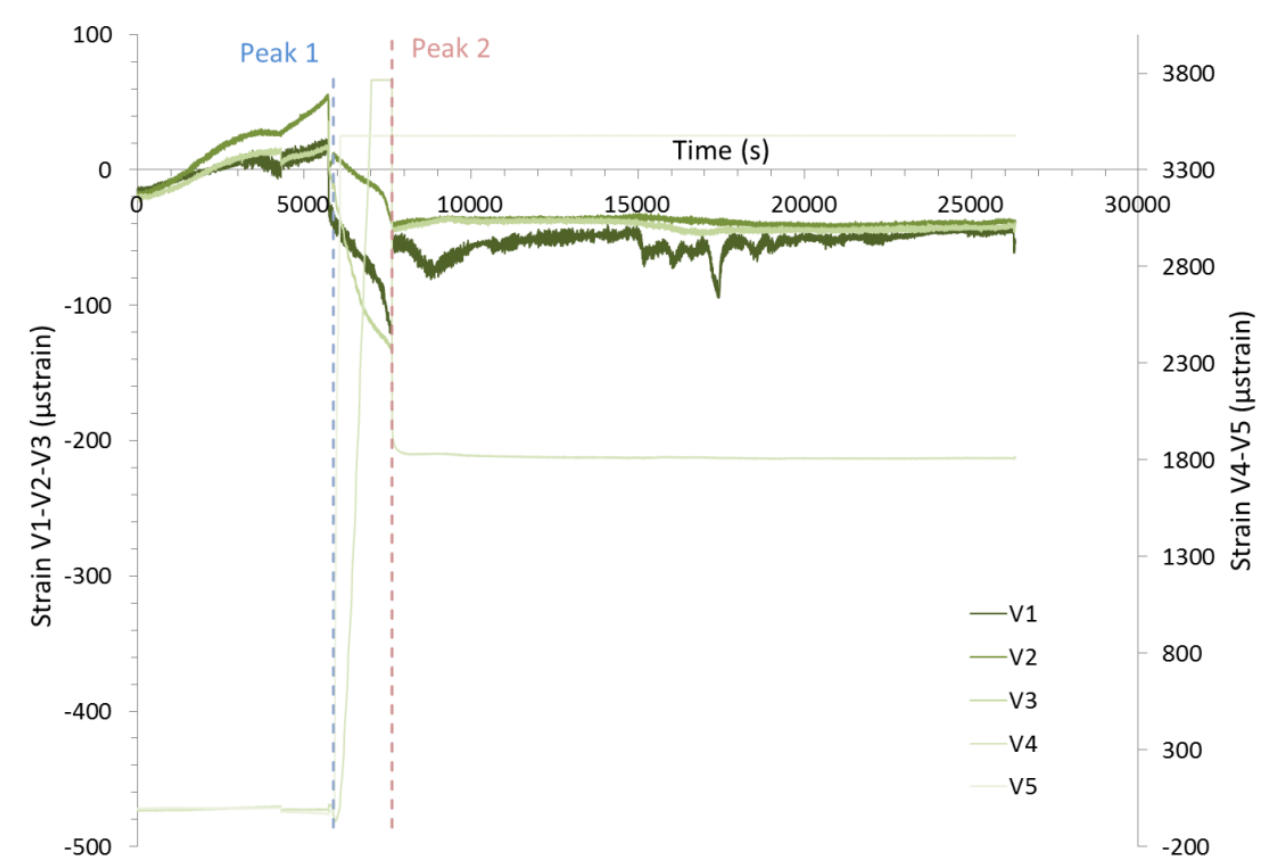

Figure 9. Strain measurement in the vertical strain gauges.

At different steps of the shear test, the AE data analysis enabled the 2D localization of the acoustic events in a plane parallel to the shear plane and in parallel, the 2D strain distributions in the concrete close to the interface were extrapolated from the measurements of the optical fiber (Mouzannar et al., 2016). Before peak 1, the AE events were concentrated on the opposite-to-push side (Fig. 10(a)), whereas the rest of the interface surface was compressed according to fiber optical measurements (Fig. 10(b)). It confirms the hypothesis that the peak 1 corresponds to a first local failure. After peak 1 , few AE events were monitored (Fig. 10(c)), when a significant increase in compression was observed in the most part of the contact surface and a crack opening was detected in concrete in the opposite-topush side (Fig. 10(d) - black line). Just before peak 2 (Fig. 10(e)), AE events were more concentrated in the central area and in the push side, exhibiting the failure occurred in the center of the interface at peak 2. After peak 2 (Fig. 10(f)), the tensile zones became compression zones and there was a global strain relaxation. 

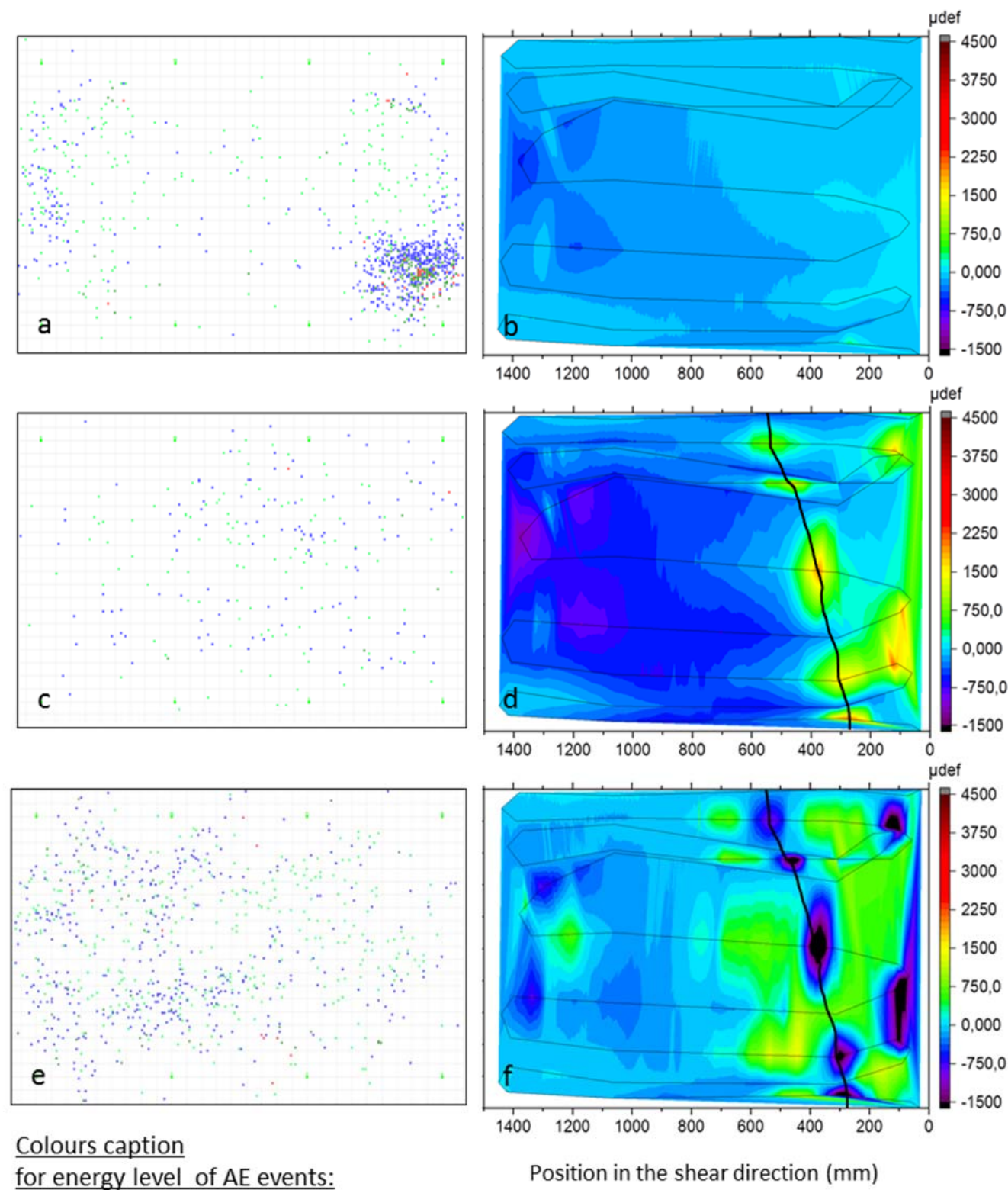

\section{Colours caption \\ for energy level of AE events:}

Position in the shear direction ( $\mathrm{mm}$ )

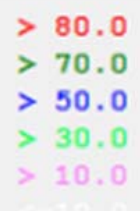

Figure 10. 2D localization of $\mathrm{AE}$ events (on the left) and strain distribution in concrete (on the right), at the interface and at four different moments of the shear test: (a)-(b) before peak 1, (c)-(d) after peak 1, (e) before peak 2, (f) after peak 2. The shear direction is from the left to the right.

Bearing in mind the topography of the rock surface used to manufacture the interface for sample I7 (Fig. 5), it can be concluded that the local rock crest on the opposite-to-push side was first damaged at peak 1 by developing a crack in rock at the base of the crest that was then propagated in concrete. 
Between the peaks 1 and 2, stresses were relaxed in this damaged area. The shear load was thereby reported on the central part of the interface constituted of the main convex asperity of the rock surface (in blue on Fig. 5). The peak 2 corresponds to the integral debonding of this central part of the concrete-rock interface. The peak 3 corresponds to the beginning of the usual residual phase corresponding to the shear of an open discontinuity.

4. Shear strength model from laboratory to metric scale

As the same type of concrete-rock interface was sheared in different smaller scales in Mouzannar et al. (2017), the shear strength values of the interface determined in these different scales were compared.

4.1. Sensitivity of the Mohr-Coulomb failure criterion to the evaluation scale

Table 4. Peak and residual strengths for each direct shear test in the metric scale.

\begin{tabular}{|c|c|c|c|}
\hline Test & $\begin{array}{c}\text { Normal stress } \\
\mathrm{MPa}\end{array}$ & $\begin{array}{c}\text { Peak strength } \\
\mathrm{MPa}\end{array}$ & $\begin{array}{c}\text { Residual strength } \\
\mathrm{MPa}\end{array}$ \\
\hline I9 & 0.2 & 1.45 & 0.20 \\
\hline I8 & 0.4 & 1.48 & 0.20 \\
\hline I7 & 0.6 & 2.20 & 0.63 \\
\hline I2 & 0.6 & 1.80 & 0.55 \\
\hline \multirow{2}{*}{ I1 } & 1 & $>2.15$ & - \\
\cline { 2 - 4 } & 0.6 & 1.55 & 0.40 \\
\hline
\end{tabular}




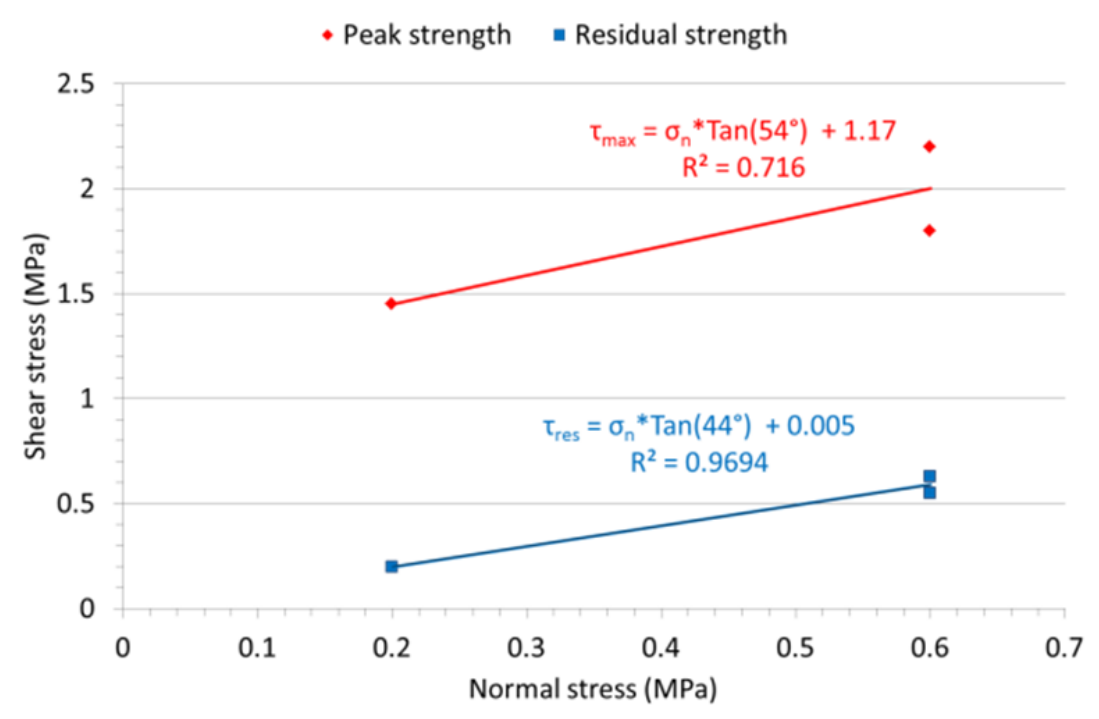

Figure 11. Mohr Coulomb failure criterion applied to peak and residual shear strengths in the metric scale.

For each direct shear test in the metric scale, the peak and residual values of the tangential stress were collected (Table 4). The peak and residual strengths were each fitted linearly by the Mohr-Coulomb failure criterion (Fig. 11). The results display the interface strength (peak or residual) increases with increasing applied normal stress. The results of the test on the sample I1 (tested first under a normal stress of $1 \mathrm{MPa}$ without complete failure, and then under 0.6 MPa) were excluded from this fitting as the interface was damaged after the first attempt to shear the sample under normal stress of $1 \mathrm{MPa}$ (Section 3.3). The values of the test on sample I8 were also not considered for this analysis since the rock surface of the interface in fact presented an altered surface (Section 2.2) and the peak shear strength depends on the quality of the bond. The peak shear strength parameters obtained (friction angle: $54^{\circ}$; cohesion: $1.17 \mathrm{MPa}$ ) are consistent with the rare in situ data with the same type of rock (Ghosh, 2010 - friction angle: $59^{\circ}$; cohesion: $1 \mathrm{MPa}$ ). 


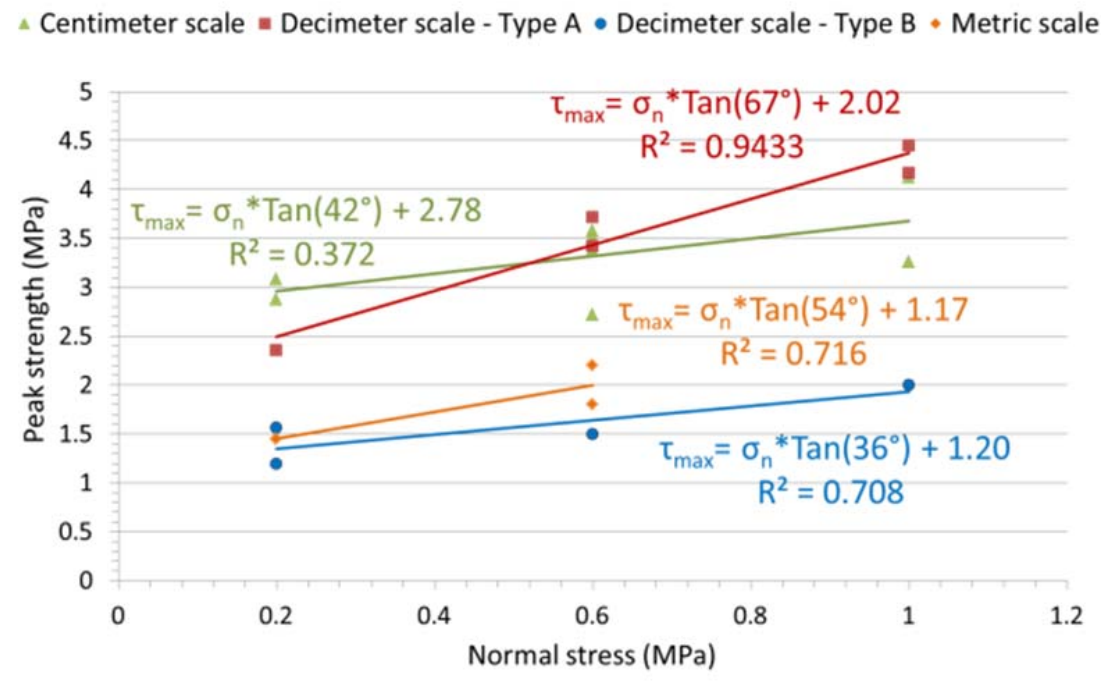

Figure 12. Mohr Coulomb failure criterion applied to peak shear strengths for different scales.

This analysis was compared with the same ones realized in the decimeter and centimeter scales (Mouzannar et al., 2017). In the decimeter scale study, the samples were discretized in Type A and Type B according to the type of the main asperities of the rock surface. Figure 12 exhibits the Mohr Coulomb failure criterion applied to peak shear strengths for the different scales. A scale effect on the peak shear strength is confirmed. However this scale effect is different considering the cohesion component or the friction angle. Taking into account the average value of cohesion for the tests in the decimeter scale, it appears that the cohesion component is subject to a negative scale effect (Fig. 12). The cohesion component decreases with increasing the size of the surfaces sheared. This last observation is in agreement with the assumption in the French recommendations (CFBR, 2012): the actual field cohesion component is considered lower than the value measured with small specimen in the laboratory. As discussed in Mouzannar et al. (2017), it is related to both an effect of the rock surface morphology, which leads to mobilize heterogeneously the initial contact bond, and a scale effect on the tensile strength value of the concrete-rock contact. By considering the average value of the friction angle in the decimeter scale, there is a positive scale effect on the value of friction angle (Fig. 12). 
Table 5. Parameters of the Mohr-coulomb criterion applied to residual behaviour for the three different scales.

\begin{tabular}{|c|c|c|}
\hline Test scale & $\begin{array}{c}\text { Residual friction angle } \\
\circ\end{array}$ & $\begin{array}{c}\text { Shear strength without normal stress } \\
\mathrm{MPa}\end{array}$ \\
\hline $\begin{array}{c}\text { Centimeter scale } \\
\text { Decimeter scale-type } \\
\text { A }\end{array}$ & 36 & 0.12 \\
\hline $\begin{array}{c}\text { Decimeter scale-type } \\
\text { B }\end{array}$ & 45 & 0.09 \\
\hline Metric scale & 46 & 0.03 \\
\hline
\end{tabular}

Concerning residual behaviour (Table 5), as the loading conditions in direct shear test on cored samples in the centimeter scale being difficult to be controlled (Mouzannar et al., 2017), it seems consistent to consider that there is no scale effect. For the concrete-rock interface in this study, the friction angle is equal to $45^{\circ}$. Moreover, the residual shear strength without normal stress is confirmed to be about zero. The residual failure criteria being without initial cohesion, it can be concluded that, under low normal load, the residual behaviour results on the purely frictional behaviour of the unbonded concrete-rock contact. This result is consistent with the conclusions of Johansson (2016) with rock joints without bond. As the roughness differs according to the observation scale, it can be also concluded that, whatever the scale, the residual strength of the concrete-rock interface depends on the roughness of the rock surface on a reduced scale and not in the large one.

4.2. Effect of roughness in the decimeter scale on the shear behaviour in the metric scale

For this rock-granite interface, in the decimeter scale and under low normal stress, Mouzannar et al. (2017) demonstrated that two different morphologies of the rock surface justify the two different shear behaviours observed. If the value of the inclination angle of the downhill faces of the main asperities in this decimeter scale is higher than $12^{\circ}$, the failure mechanism is type B. In this case, the inclination angle is so large that the local normal tensile stress on the downstream side of the rock surface main asperities, resulting from the applied tangential force, is significant and may reach the tensile strength 
of the concrete-rock contact. If the value of the inclination angle is lower than $9^{\circ}$, the failure mechanism is type A. The inclination angle being lower, for the same value of the tangential force applied, the local normal tensile stress in these areas will be lower contrary to the shear stress higher. Thus, for lower inclination angle, a larger tangential force will be required to reach the shear strength of the concrete-rock contact. For type A, failure locally occurs mainly in shear and for type B, failure locally occurs mainly in tension.

The scatter of the values of peak shear strength assessed in the metric scale for the same rock-granite interface (Fig. 12 - orange line) is not so important to justify a similar discretization in two types according to roughness. However these values are actually in-between the shear strengths envelopes of the two types of failure behaviour, A and B, assessed in the decimeter scale (Fig. 12 - red line for type A and blue one for type B). To take account the roughness on a reduced scale for the evaluation of the shear strength in the metric scale, the values of shear strength in the decimeter scale for both type A and $\mathrm{B}$ behaviours being given, it was suggested to consider a combination of the shear strengths values measured in the decimeter scale. Considering concrete-rock interface being not completely bonded, Lo et al. (1990) evaluated the concrete-rock interface shear strength as the sum of the well bonded concrete-rock contact shear strength and unbonded concrete-rock contact shear strength. Introducing the ratio of the unbonded contact surfaces to the total area of contact, they considered that the shear strength resulted, for a fraction of the contact area, from Patton (1966) failure criterion, plus for a fraction of the contact area, from the Coulomb friction criterion. Similarly, an analytical model for shear strength of the large-scale concrete-rock interface was proposed by summing the shear strength of the Type A and the shear strength of the Type B in the decimeter scale :

$$
\tau_{-} \max \left(\sigma_{n}\right)=\Omega \times \tau_{-} A\left(\sigma_{n}\right)+(1-\Omega) \times \tau_{-} B\left(\sigma_{n}\right)
$$

where:

- subdividing the rock surface of the large-scale samples into elementary surfaces with dimensions of the order of those of the samples used in the decimeter scale tests, $\Omega$ is the fraction of the elementary surfaces compared to the total area which exhibit the type A shear 
behaviour and $(1-\Omega)$, the fraction of the elementary surfaces compared to the total area which exhibit the type B shear behaviour;

- $\quad \tau_{-} A$ is the peak shear strength of the type A concrete-rock interface behaviour measured in the decimeter scale;

- $\tau_{-} B$ is the peak shear strength of the type B concrete-rock interface behaviour measured in the decimeter scale;

- $\sigma_{n}$ is the normal stress.

Thus each large-scale rock surface tested was discretized into small square windows of dimension $0.25 \mathrm{~m}$, namely the same magnitude of the rock surfaces dimensions tested in the decimeter scale: 0.18 $\mathrm{m} \times 0.18 \mathrm{~m}$ (Mouzannar et al., 2017). For each window, the elementary surface topography was represented with respect to its own best fit mid-plane calculated by the least squares method. Then, each elementary surface was analyzed by using the Mouzannar et al. (2017) rock surface morphology characterization to define its type, A or B. The ratio $\Omega$ was finally determined as the number of elementary surfaces with the type A behaviour divided by the total number of elementary surfaces. This approach was applied to the four rock surfaces of the interfaces I7, I2, I8 and I9 (Table 6), which were tested under low normal stresses $(\leq 0.6 \mathrm{MPa})$.

Table 6. Comparison between experimental data and results of the analytical model.

\begin{tabular}{|c|c|c|c|c|c|c|c|}
\hline Surface & $\begin{array}{c}\text { Normal } \\
\text { stress } \\
\mathrm{MPa}\end{array}$ & $\Omega$ & $\begin{array}{c}\text { Type A } \\
- \\
\text { peak } \\
\text { strength } \\
\mathrm{MPa}\end{array}$ & $\begin{array}{c}\text { Type B }- \\
\text { peak } \\
\text { strength } \\
\mathrm{MPa}\end{array}$ & $\begin{array}{c}\text { Analytical } \\
\text { peak strength } \\
\mathrm{MPa}\end{array}$ & $\begin{array}{c}\text { Experimental } \\
\text { peak strength } \\
\mathrm{MPa}\end{array}$ & $\begin{array}{c}\text { Relative } \\
\text { standard } \\
\text { deviation } \\
\%\end{array}$ \\
\hline $\mathrm{I} 7$ & 0.6 & 0.29 & 3.40 & 1.64 & 2.15 & 2.20 & 2.30 \\
\hline I2 & 0.6 & 0.25 & 3.40 & 1.64 & 2.08 & 1.80 & 14.43 \\
\hline I8 & 0.4 & 0.33 & 2.94 & 1.49 & 1.97 & 1.48 & 28.40 \\
\hline I9 & 0.2 & 0.29 & 2.47 & 1.34 & 1.67 & 1.45 & 14.10 \\
\hline
\end{tabular}

For all the four large scale samples, most of the elementary surfaces have a morphology leading to a Type B behaviour during shear $(1-\Omega \sim 70 \%$ ), which explains that the peak shear strength criterion from the large-scale tests is close to that from the decimeter scale tests of Type B behaviour. 
Based on the tests in the decimeter scale, the proposed analytical approach gives a good estimate of the large-scale shear strength observed for the concrete-rock interfaces of the three samples I7, I2 and 19. The relative standard deviation between analytical and experimental results is close to zero for the interface I7 and equal to $14 \%$ for both I 2 and I9. These values are considered to be consistent. This confirms the assumption that the large-scale peak shear strength is dependent on the local shear strength behaviour, related to the rock surface morphology in this decimeter scale.

The deviation between the analytical estimate and measured value for the peak strength of the interface I8 is larger $(28.4 \%)$. In fact, the rock surface of the interface I8 was weathered and failure occurred primarily within the weathered rock surface. This explains why the analytical approach gives a value higher than the experimental result.

\section{Discussions and conclusions}

Under low level of normal stress in the metric scale, except for rare asperities isolated and localized, the shear failure of the concrete-rock interface occurs along the concrete-rock contact and not in the shear plane imposed by the shear box (Section 3.1). Considering the main asperities of the interfaces in the metric scale and the Mouzannar et al. (2017) rock surface morphology characterization, no similar discretization to the one observed in the decimeter scale (Section 4.1) is to notice. The metric scale is not the relevant observation way to address the shear behaviour of these interfaces. Actually, for this case study, the shear behaviour in the metric scale can be explained by the shear behaviour observed in the decimeter scale (Section 4.2).

In the analysis of the stress state in the decimeter scale, Mouzannar et al. (2017) demonstrate that the main morphology of the contact surface and the bond are linked in mobilizing stress. Under a low level of normal stress, according to the inclination angle of main asperities, the bond between concrete and rock is loaded in tension or in shear. The strength to both load cases being different, the local failure is heterogeneous along the contact for a metric rock-concrete interface. In previous works (Krounis et al., 2015), authors linked the heterogeneity of the interface shear strength to that of the 
contact bond. These works demonstrate that the heterogeneity of stress state in the decimeter scale (Section 4.2) justifies the local heterogeneity of the interface shear strength in the metric scale and the value of metric interface shear strength.

The peak value depending on the initial quality of the rock-concrete bond (Section 3.3), these works confirm the fact that the bond between concrete and rock contributes significantly to the interface shear strength (Lo et al., 1990; Moradian et al., 2012; Saiang et al., 2005; Tian et al., 2015; Krounis et al., 2016). Consequently, for the shear strength of the interface between gravity dam and rock foundation, the design offices could introduce a cohesion parameter. However, as the interface bond is observed to be partially reduced by load (Section 3.3) and its failure to be brittle (Section 3.2), a safety factor should be introduced to take account the low dependability of this contribution to the interface shear strength.

The shear behaviour of bonded concrete-rock interface was investigated by performing five direct shear tests on metric samples. Appropriate instrumentation and careful samples preparation allow the failure mechanisms to be observed. Considering previous results obtained with similar interfaces sheared in the centimeter and decametric scales, an analytical model was proposed to evaluate the shear strength of concrete-rock interface in the metric scale. The main conclusions of this work are the followings:

- the shear strength of concrete-rock interface in the metric scale evaluated by considering the friction angle determined on a lower scale and having nearly zero cohesion is strongly conservative;

- under low normal stress as that generated on the base of gravity dams, the shear failure mechanism of concrete-rock interface is governed by the bond between concrete and rock. This bond is differently mobilized according to the roughness of the contact surface;

- an intermediate surface of the contact can be considered as representative of the shear failure mechanisms of concrete-rock interface. In this study case, the decimeter scale seems to be a 
relevant observation scale. This relevant scale is certainly a consequence of the normal stress, roughness of the contact surface and material deformability. The role of material which was identified as important in previous works (Singh et al., 2017), was not investigated in this study.

\section{Acknowledgment}

This work was funded by a contract from EDF.

Notations

$\Omega=$ Fraction of the elementary surfaces compared to the total area which exhibit the type A shear behaviour

$\sigma_{n}=$ Normal stress

$\tau_{-} A=$ Peak shear strength of the type A concrete-rock interface behaviour measured in the decimeter scale

$\tau_{-} B=$ Peak shear strength of the type B concrete-rock interface behaviour measured in the decimeter scale

$\tau_{\max }=$ Peak shear strength

$\tau_{\text {res }}=$ Residual shear strength

\section{References}

Andjelkovic, V., Pavlovic, N., Lazarevic, Z., and Nedovic, V. (2015). "Modelling of shear characteristics at the concrete-rock mass interface." International Journal of Rock Mechanics and Mining Sciences, Vol. 76, pp. 222-236, DOI: 10.1016/j.ijrmms.2015.03.024.

ASTM. (2008). Standard test method for performing laboratory direct shear strength test of rock specimens under constant normal force, D5607 - 08, ASTM International, West Conshohocken, PA, DOI: $10.1520 / \mathrm{D} 5607-08$. 
Bandis, S., Lumsden, A.C., and Barton, N.R. (1981). "Experimental studies of scale effects on the bahavior of rock joints.” International Journal of Rock Mechanics Mining Sciences \& Geomechanics abstracts, 18, pp. 1-21, DOI: 10.1016/0148-9062(81)90262-X.

Barbosa, R. E. (2009). “Constitutive model for small rock joint samples in the lab and large rock joint surfaces in the field." Proceedings of the 3rd CANUS Rock Mechanics Symposium, Ed: M.Diederichs and G.Grasselli, Toronto.

Barla, G., Robotti. F., and Vai., L. (2011). "Revisiting large size direct shear testing of rock mass foundations." Proc. of 6th International Conference on Dam Engineering, C.Pina, E.Portela, J.Gomes (ed.), Lisbon, Portugal.

Barton, N., and Choubey, V. (1977). "The shear strength of rock joints in theory and practice." Rock Mechanics, 10, pp. 1-54, DOI: 10.1007/BF01261801.

Brown, E. T. (2017) "Reducing risks in the investigation, design and construction of large concrete dams." Journal of Rock Mechanics and Geotechnical Engineering, 9, pp. 197-209, DOI: 10.1016/j.jrmge.2016.11.002.

Casagrande, D., Buzzi, O., Giacomini, A., Lambert, C., and Fenton, G. (2017). “A New Stochastic Approach to Predict Peak and Residual Shear Strength of Natural Rock Discontinuities.” Rock Mechanics and Rock Engineering, pp. 1-31, DOI: 10.1007/s00603-017-1302-3.

Castelli, M., Re, F., Scavia, C., and Zaninett, A. I. (2001). "Experimental evaluation of scale effects on the mechanical behavior of rock joints." Proceedings of Eurock 2001 Rock Mechanics - A Challenge for Society, Espoo, Finland.

CDA (2007). Structural considerations for dam safety, Technical bulletin, Canadian Dam Association.

CFBR (2012). "Recommendations for the justification of the stability of gravity dams", ISBN 979-1096371-03-7.

Chataigner, S., Gaillet, L., Falaise, Y., David, J.-F., Michel, R., Aubagnac, C., Houel, A., Germain, D., and Maherault, J.-P. (2017). “Acoustic monitoring of a pre-stressed concrete beam reinforced by adhesively bonded composite." SMAR 2017, the 4th International Conference on Smart Monitoring, Assessment and Rehabilitation of Civil Structures, Zurich, Suisse, 8 p. 
Chen, S. H., Yang, Z. M., Wang, W. M., and Shahrour, I. (2011). "Study on Rock Bolt Reinforcement for a Gravity Dam Foundation.” Rock Mechanics and Rock Engineering, 45. DOI: 10.1007/s00603-011$\underline{0179-9}$.

Cravero, M., Iabichino, G., and Piovano, V. (1995). “Analysis of large joint profiles related to rock slope instabilities." Proc. of 8th ISRM Congress, Tokyo, Japan.

EDF (2012). Barrage du RIZZANEZE: Rapport géologique de réalisation du fond de fouilles, Internal technical note, EDF-TEGG, n EDTGG110070 B, 38 p.

EPRI (1992). Uplift pressures, shear strengths and tensile strengths for stability analysis of concrete gravity dams, Vol. 1., Electrical Power Research Institute, Stone and webster engineering corporation ed., Denver, Colorado.

Fardin, N., Stephansson, O., and Jing, L. (2003). "Scale effect on the geometrical and mechanical properties of rock joints." Proc. Of ISRM 2003 - Technology roadmap for rock mechanics, South African Institute of Mining and Metallurgy, pp. 319-324.

FERC (2002) Engineering guidelines for the evaluation of hydropower projects, Chapter III - gravity dams, The federal energy regulatory commission ed.

Ghosh, A. K. (2010). "Shear strength of dam-foundations rock interface - A case study." Proc. of Indian geotechnical conference, GEOtrendz, IGS Mumbai Chapter \& IIT Bombay.

Grasselli, G. (2001). Shear strength of rock joints based on quantified surface description, PhD Thesis, Ecole Polytechnique Fédérale de Lausanne, Switzerland.

Gu, X. F., Seidel, J. P., and Haberfield, C. M. (2003). "Direct shear test of sandstone-concrete joints." International Journal of Geomechanics, 3(1/2), pp. 21-33. DOI: 10.1061/(ASCE)1532$\underline{3641(2003) 3: 1(21)}$.

Gutiérrez, M. C. (2013). Shear resistance for concrete dams, Master Thesis, Norwegian University of Science and Technology, Norway.

Gutierrez-Ch, J.G., Senent, S., Melentijevic, S., and Jimenez, R. (2018). "Distinct element method simulations of rock-concrete interfaces under different boundary conditions." Engineering Geology, 240, pp. 123-139, DOI:10.1016/j.enggeo.2018.04.017. 
Hencher, S. R., Toy, J. P., and Lumsden, A. C. (1993). "Scale dependent shear strength of rock joints." Proceedings of the 2nd International Workshop on Scale Effects in Rock Masses, Lisbon, Portugal, pp. $233-41$.

Johansson, F. (2016). "Influence of scale and matedness on the peak shear strength of fresh, unweathered rock joints.” International Journal of Rock Mechanics and Mining Sciences, Vol. 82, pp. 36-47, DOI: 10.1016/j.jirmms.2015.11.010.

Khadour, A, and Waeytens, J. (2017). "Monitoring of concrete structures with optical fiber sensors." Ecoefficient Repair and Rehabilitation of Concrete Infrastructures, Chapitre 5, Woodhead Publishing Series in Civil and Structural Engineering, Elsevier Science, pp. 97-121.

Kodikara, J.K., and Johnston, I.W. (1994). "Shear behaviour of irregular triangular rock-concrete joints." International Journal of Rock Mechanics and Mining Sciences \& Geomechanics Abstracts, Vol. 31, Issue 4, pp. 313-322, DOI: 10.1016/0148-9062(94)90900-8.

Krounis, A., Johansson, F., and Larsson S. (2015). "Effects of spatial variation in cohesion over the concrete-rock interface on dam sliding stability." Journal of Rock Mechanics and Geotechnical Engineering, 7, DOI: 10.1016/j.jrmge.2015.08.005.

Krounis, A. (2016). Sliding stability re-assessment of concrete dams with bonded concrete-rock interfaces, PhD Thesis, KTH Royal Institute of Technology, Stockholm, Sweden.

Krounis, A., Johansson, F., and Larsson, S. (2016). "Shear strength of partially bonded concrete-rock interfaces for application in dam stability analyses." Rock Mechanics and Rock Engineering, 49(4), pp.1-12, DOI: $10.1007 / \mathrm{s} 00603-016-0962-8$.

Lo, K. Y., Lukajic, B., Wang, S., Ogawa, T., and Tsui, K. K. (1990). "Evaluation of strength parameters of concrete-rock interface for dam safety assessment" Proceedings of Canadian Dam Safety Conference, Toronto, Canada.

Maksimovic, M. (1996). “The shear strength components of a rough rock joint.” International Journal of Rock Mechanics and Mining Sciences, 33(8), pp. 769-783, DOI: 10.1016/0148-9062(95)00005-4.

Moradian, Z., Ballivy, G., and Rivard, P. (2012). "Application of acoustic emission for monitoring shear behavior of bonded concrete-rock joints under direct shear test." Canadian Journal of Civil Engineering, 39 (8), pp. 887-896, DOI: 10.1139/12012-073. 
Mouzannar, H., Bost, M., Joffrin, P., Pruvost, C., Rojat, F., Blache, J., Houel, A., Valade, M., Khadour, A., Chataigner, S., David, J.F., and Quiertant, M. (2016). "Instrumentation of large scale direct shear test to study the progressive failure of concrete/rock interface." Proc. of 8th RILEM International Conference On Mechanism of Cracking and Debonding in Pavements, Nantes, France, DOI: 10.1007/978-94-024-0867-6 91.

Mouzannar, H., Bost, M., Leroux, M., and Virely, D. (2017). "Experimental study of the shear strength of bonded concrete-rock interfaces: surface morphology and scale effect." Rock Mechanics and Rock Engineering, 50(10), pp. 2601-2625, DOI: 10.1007/s00603-019-01951-0.

Muralha, J., Grasselli, G., Tatone, B., Blümel, M., Chryssanthakis, P., and Yujing, J. (2014). "ISRM Suggested method for laboratory determination of the shear strength of rock joints: revised version." Rock Mechanics and Rock Engineering, 47(1), pp. 291-302, DOI: 10.1007/s00603-013-0519-z.

Patton, F. D. (1966). "Multiple modes of shear failure in rock." Proc. of 1st Congress of International Society of Rock Mechanics, p. 509-513.

Pratt, H.R., Black, A.D., and Brace, W.F. (1974). "Friction and deformation of jointed quartz diorite." Proc. of 3rd ISRM Congress on Rock Mechanics, II-A, pp. 306-310.

Ruggeri, G., Pellegrini, R., Rubin de Celix, M., Berntsen, M., Royet, P., Bettzieche, V., Amberg, W., Gustafsson, A., Morison, T., and Zenz, A. (2004). "Sliding stability of existing gravity dams - final report." ICOLD European Working group on sliding safety of existing gravity dams.

Saiang, D., Malmgren, L.,and Nordlund, E. (2005). "Laboratory tests on shotcrete-rock joints in direct shear, tension and compression.” Rock Mechanics and Rock Engineering, 38 (4), pp. 275-297, DOI: 10.1007/s00603-005-0055-6.

Schleiss, A. J., and Pougatsch, H. (2011). Les barrages - Du projet à la mise en service. Traité de Génie Civil de l'Ecole Polytechnique Fédérale de Lausanne - Volume 17, Presses Polytechniques et Universitaires Romandes.

Singh, H., and Basu, A. (2017). "A Comparison between the shear behavior of 'real' natural rock discontinuities and their replicas." Rock Mechanics and Rock Engineering, 51, pp. 1-12, DOI: $10.1007 / \mathrm{s} 00603-017-1334-8$. 
Swan, G., and Zongqi, S. (1985). "Prediction of shear behavior of joints using profiles." Rock Mechanics Rock Engineering, 18 (3), pp. 183-212, DOI: 10.1007/BF01112506.

Tatone, B. S. A., Grasselli, G., and Cottrell, B. (2010). "Accounting for the influence of measurement resolution on discontinuity roughness estimates.” Proc. of ISRM International Symposium - EUROCK 2010, Lausanne, Switzerland.

Tatone, B. and Grasselli, G. (2013). "An investigation of discontinuity roughness scale dependency using high-resolution surface measurements.” Rock Mechanics Rock engineering, 46, pp. 657-681, DOI: $\underline{10.1007 / \mathrm{s} 00603-012-0294-2 .}$

Tian, H. M, Chen, W. Z., Yang, D. S , and Yang J. P. (2015). "Experimental and numerical analysis of the shear behaviour of cemented concrete-rock joints.” Rock Mechanics Rock Engineering, 48, pp. 213222, DOI: $10.1007 / \mathrm{s} 00603-014-0560-6$.

Tian, Y., Liu, Q., Liu, D., Kang, Y., Penghai, D., He, F. (2018). “Updates to Grasselli's Peak Shear Strength Model.” Rock Mechanics and Rock Engineering, 51, DOI: 10.1007/s00603-018-1469-2.

Westberg Wilde, M., and Johansson, F. (2013). "System reliability of concrete dams with respect to foundation stability: application to a spillway." Journal of Geotechnical and Geoenvironmental Engineering, 139(2), pp. 308-319, DOI: 10.1061/(ASCE)GT.1943-5606.0000761.

Zhao, W., Chen, W., and Zhao, K. (2018). "Laboratory test on foamed concrete-rock joints in direct shear." Construction and Building Materials, 173, pp. 69-80, DOI: 10.1016/j.conbuildmat.2018.04.006. 